\title{
ARTIFICIAL INTELLIGENCE AS A TOOL FOR EVALUATING THE EFFICIENCY OF INNOVATIVE TECHNOLOGIES FOR HARD-TO-RECOVER RESERVES DEVELOPMENT
}

\author{
CHERNYAEV V.Maxim", MAZURCHUK M.Timofey ${ }^{2}$, BOIKO A.Aleksandra ${ }^{3}$ \\ ${ }^{1}$ Faculty of Economics, Peoples' Friendship University of Russia (RUDN University), Moscow (RUSSIAN FEDERATION) \\ ${ }^{2}$ Faculty of Economics, Peoples' Friendship University of Russia (RUDN University), Moscow (RUSSIAN FEDERATION) \\ ${ }^{3}$ Faculty of Economics, Peoples' Friendship University of Russia (RUDN University), Moscow (RUSSIAN FEDERATION) \\ E-mails: chernyaev-mv@rudn.ru;1042200121@rudn.university;1042200243@pfur.ru
}

\begin{abstract}
The possibility of artificial intelligence use for improvement of efficiency of development of hard-torecover reserves in Russian oil and gas complex are considered in research article. The share of hard-torecover reserves increases annually in cumulative oil production in the territory of the Russian Federation, therewith ups and downs of prices for oil well-known brands increase the risks of unforeseen costs and material losses when developing new reserves, that is why the authors establish a goal to analyze the efficiency of geological exploration and development of oil hard-to-recover reserves using artificial intelligence technologies and also based on the calculation of a comparative model for assessing the use of artificial intelligence on groups of fields of the Bazhenov formation.

Artificial intelligence can have a beneficial effect on decrease of human error risk when selecting potential cased holes and facilitate in choosing the best methods of development and feed production stimulation. As a result of the comparative assessment of the return on investment in the development of wells using artificial intelligence and traditional technologies, the advantages and disadvantages of AI technologies were identified in the context of increasing the economic efficiency of hard-to-recover oil production.
\end{abstract}

Keywords: HTR, hydrocarbons, artificial intelligence, oil production innovations, petroleum production stimulation

JEL: 030

DOI: 10.5937/intrev2103030C

UDC: $338.45: 622.323(470)$

005.93:004.896

COBISS.SR-ID 55056905 


\section{INTRODUCTION}

In the immediate future, hard-to-recover reserves of oil (hereinafter referred to as "HTR") will form the basis of oil and gas production in Russia, hard-to-recover reserves of hydrocarbons exceeded $65 \%$ of total production level already in 2020, and according to the projections of experts of RF Ministry of Energy, their share will increase up to $80 \%$ at Russian fields by 2035 . Companies' expenses for HTR production also increase, and in conditions of hydrocarbon worldwide market unsteadiness and leap in prices for oil wellknown brands companies may have an experience when oil production can become profitless. [1]

To decrease the production cost, Russian oil and gas companies carry out researches in the field of artificial intelligence, "Big Data" and "Blockchain" technologies use during geologic exploration, new fields' developments and stimulation of production at current ones in purpose to exclude the "human error" factor and minimization of risks from economic losses from potentially illiquid fields and feed technologies optimization and production methods.

The topic touched upon by the authors is relevant for improving the efficiency of the entire oil and gas industry in Russia, as well as the application of the results obtained in other countries of the world. To achieve the goal of the scientific research, the authors apply on: analysis of the current state of development and application of AI technologies in Russia and abroad; development of a method for assessing the effect of the use of digital initiatives; determining the necessary conditions for achieving economic feasibility and positive results of the introduction of artificial intelligence technologies which are the main tasks for assessing the economic efficiency of using artificial intelligence technologies in the production of hard-torecover hydrocarbons.

\section{MATERIALS AND METHODS}

This research technique implementation consists in assessment of possibilities of artificial intelligence use and related innovative solutions when developing oil-and-gas fields. The research is based on the analysis of data on usage of technologies mentioned above at Bazhenov suit fields group, where experiments on training and development of AI are performed. Tools set for research performance include: search and analysis of necessary information, assessment of oil, oil-associated and natural gas production efficiency. Based on the AI technologies suggested, the results are compared on the basis of created reference assessment framework for efficiency of HTR development with AI and averaged data from the similar fields without usage of innovation technologies. The calculation includes the ratio of discounted indicators of costs and benefits, taking into account the assessment of the digital component. [2]

Scientific sources of both Russian and foreign authors, oil and gas companies' reports, data of Russian Federal Ministries, as well as industry experts assessments have become the information and statistic base of research. At this point in time there is no publicly available methodology for using AI in the production of hard-to-recover hydrocarbons and full-fledged results of technology approbation with a description of the AI implementation mechanism, the authors rely on statistical data published before and after the use of artificial intelligence technologies based on a group of fields in the Bazhenov Formation, as well as expert assessments and forecasts for the development of these technologies by the state and companies.

\section{RESULTS}

Determination of the trajectory of innovative technologies development in the oil and gas complex, creation of the necessary technological basis for the complex systems functioning based on artificial intelligence in the oil and gas complex of Russia. Analysis of the current state of AI technologies development and highlighting the advantages and disadvantages in terms of increasing economic efficiency of HTR production in Russia.

Creation of a reference framework for assessment of artificial intelligence use at Bazhenov suit fields group. Comparative assessment of the return on investment in the field, carried out by the least squares method, showed that the return on investment when developing a well using artificial intelligence exceeds that when using traditional well development technologies by an average of $16 \%$. 
Also, the results of this study can serve as a basis for building more complex models for assessing the implementation of AI in hydrocarbon production and allow projecting the research experience for the development of new fields in similar climatic and geographical conditions.

\section{DISCUSSION}

Since 2014, an active program of key technologies import substitution in the oil and gas sector has begun in Russia. The first steps in the strategy taken by the state were mainly in heavy industry (drilling rigs, pipelines, equipment for reserves exploration, etc.). Since 2017, the updated strategy of import substitution has included the following items: software, tools increasing the efficiency of HTR production and reduction of the risks of "illiquid wells" introduction, that is, wells where it is impossible to achieve the required level of debit. The experts of PJSC "Gazprom Neft", PJSC "Rosneft" and a number of other Russian companies have combined the all the listed elements in consolidated projects of innovative intelligent systems for collecting and analyzing information using a number of technologies previously used in Russia only in IT area. [3]

However, it was not only the development of an import substitution strategy that stimulated oil and gas companies to invest and develop the IT area. The Russian oil and gas industry has accumulated large amounts of sophisticated data obtained during the development of oil and gas fields, but companies could hardly use such amount of information, due to the inconsistency of factors and databases. [2]

Thus, since 2015, PJSC "Rosneft" has been using its own AI developments for offshore oil and gas projects with analysis with the Blockchain system, which transmits real-time data from all mobile platforms taking into account seismic activity and water fluctuations to adjust equipment on all platforms in the production region quickly. Computer systems are installed on each platform, which allows independent calculations performing without transfer to a single center and excluding the possibility of data capture by third-party agents. The introduction of the system in accordance with the statistical reporting data allowed 2.3 times reduction of time for adjusting the equipment and the rate of feed production increase. [4 p.559]

However, the above technology involves only a small segment of oil and gas production data. The Director of "Gazprom Neft" Alexander Dyukov has commented on the works on AI as follows: "The development of universal AI-based software was caused by the need to ensure the Russian oil and gas complex independence from the equipment and software licenses import and challenged itself to combine all information clusters of the company into an integrated system in which processes can proceed with minimal human participation and at such speeds that decisions will be made in seconds." [ 5 p.30]

Indeed, the software is the most vulnerable area of OGC. Thus, according to experts, "Dependence on foreign software products in the oil and gas industry, according to average assessments, is about $85-90 \% . "$ [6 p.222-223] A number of Russian companies: "Rosneft", "Gazprom Neft", "Lukoil" and "Tatneft" are introducing $\mathrm{AI}$ and other high-tech systems.

Before analyzing Russian experience, we can refer to foreign companies and consider examples of the technologies effective introduction by other world transnational corporations in the area of hydrocarbon production. The experience of innovative technologies introduction is widespread in the global market and many IT companies provide oil and gas transnational corporations with their developments, computing powers and servers.

That is how AI "intuitively" integrates information, reveals new connections and processes, and uses it to create an up-to-date map of the mineral assets of the Company "British Petroleum". Based on the results of AI operation, the oil company refer the statistical base generated by AI using neural networks to simulate and interpret the results for each current and potential oil production project of the company. [3]

"ExxonMobil" uses "Big Data" technology for storing and processing data from all its fields. AI analyses 130 terabyte of data and covers more than 13,000 wells, 5,200 seismic researches and 3,500 pipelines. "ExxonMobil" uses AI to interpret this data. The company representatives report that they will be able to open new oil and gas fields with its help and increase the production of existing infrastructures in the future. The "ExxonMobil" platform based on AI, will become part of energy jump of the US oil and gas industry, and data on collectors and infrastructure will be a nice basis for future projects on carbon capture, use and storage. AI can also be used to improve the safety of operations on oil and gas production platforms. 
Thus, companies are trying to summarize accumulated information data that could not be collected and analyzed by a person. It should be noted that all examples above denote the phased introduction of new technologies from single deposits or sectors of OGC to the full combination of data. Moreover, the companies have received investments in generation of these structures from the states ("ExxonMobil" - 3.3 billion US dollars from 2013 to 2018 for research and development (hereinafter referred to as "R\&D"), and "British Petroleum" 1.8 billion US dollars from 2012 to 2016 for R\&D). Figure 1. below provides data on comparison of Russian and foreign state investments in innovative developments of oil and gas companies. [7]

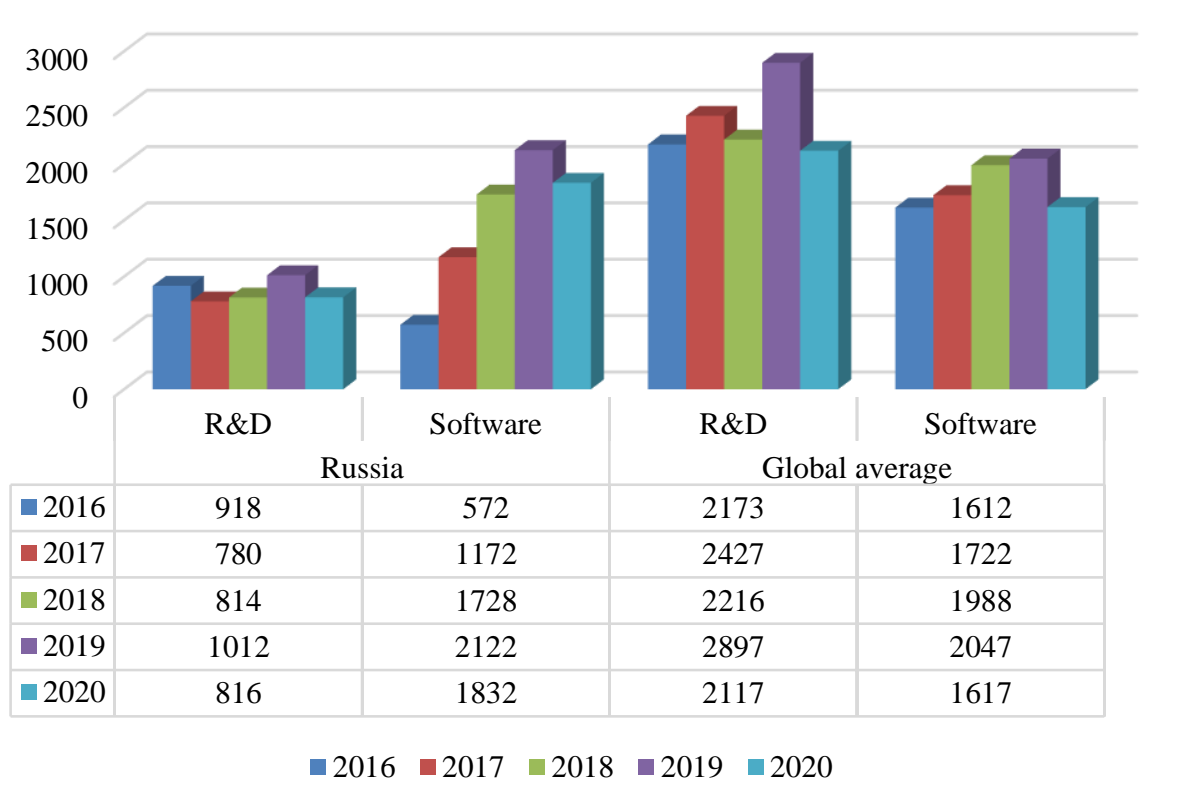

Fig . 1. Comparison of investments in $R \& D$ and software in the oil and gas complex by the state in $R \& D$ and separately in software between Russian and the global average value from 2016 to 2020 in million US dollars

Source: drawn up in accordance with data by authors $[2,8]$

The authors have analyzed the main investments from the state budget in $R \& D$ and software in Russia and according to the global average values, calculated by analysts of "British Petroleum" in the annual reports from 2016 to 2020. It should be noted that despite the underrun in total investment in Russia, there is a high growth rate, while in global practice the values fluctuate at the same level. These differences are caused by the fact that since 2014, the Russian Government has been actively supporting Russian oil exporting companies in response to sanctions restrictions and ups and downs in hydrocarbon prices, while companies have temporarily transferred to an extensive development, reducing the growth rate of investments in $\mathrm{R} \& \mathrm{D}$ to maintain profitability in global practice.

However, the current volume of investments in the Russian OGC, according to the Ministry of Energy of Russia, is not enough; a number of key technologies for HTR fields development are still purchased from foreign partners in 2020:

- Equipment for field arrangement (import share - 61\%);

- Software (import share - 91\%);

- Services for offshore projects (import share - 68\%)

- Offshore equipment (import share - 72\%);

- Catalysts for oil refining and petrochemicals (import share - 74\%). [9]

Moreover, according to the Federal State Statistics Service of the Russian Federation, the lack of server capacities in OGC is $87 \%$. This means that the companies will have to make significant investments in the purchase of computer units for data storage and analysis or throw these technologies in outsourcing, but in case of the second option, the risk of theft or loss of information increases. [4]

The first sole complex in Russia using 3 key technologies at once: "Blockchain", "Big Data" and AI was introduced by "Gazprom Neft" at the fields of the Bazhenov suit. The Bazhenov suit includes both traditional oil reserves, hard-to-recover, natural gas, as well as slate-like formations, with the largest deposits 
of slate oil and gas reserves in the world. According to assessments by the US energy agency EIA, $22 \%$ of the global slate oil (10.3 billion tons) is in Bazhen. [10]

The unified system for analyzing data on the development of experimental wells at the Bazhenov suit was the first intelligent system to which 3 Russian companies have access at once: "Gazprom Neft", "Rosneft" and "Lukoil". Despite the competition, this introduction of universal systems for analysis and exchange of information in the framework of the national production project at the Bazhenov suit was the only solution to overcome the economic barrier of hard-to-recover resources pay-back. [5]

Nevertheless, in order to determine the cost efficiency of the suggested measures, when analyzing the AI technologies used at the Bazhenov suit, data on the pay-back of investment in 60 fields were selected. (Table 1.)

Table. 1.Checking the dependence of the pay-back of investment in the field on the usage of AI or the traditional method of well development

\begin{tabular}{|l|l|l|l|l|}
\hline \multicolumn{5}{|c|}{$\begin{array}{l}\text { Estimation method: least square method } \\
\text { Selected wells: } 1-60-15 \times 1+15 \times 1 / / 15 \times 2+15 \times 2\end{array}$} \\
\hline Index & $\begin{array}{l}\text { Design } \\
\text { factor }\end{array}$ & $\begin{array}{l}\text { Standard } \\
\text { error }\end{array}$ & $\begin{array}{l}\text { Estimation of average values } \\
\text { signification }\end{array}$ & $\begin{array}{l}\text { Error } \\
\text { probability }\end{array}$ \\
\hline AI use at analyzed wells & 1.67019 & 0.28291 & 12.80390 & 0.0033 \\
\hline $\begin{array}{l}\text { Well development traditional } \\
\text { technologies }\end{array}$ & 1.43622 & 0.00472 & 18.03819 & 0.0011 \\
\hline Free factor & 0.09783 & 0.39829 & 3.40310 & 0.0294 \\
\hline
\end{tabular}

Source: drawn up in accordance with data by authors [7][8]

When calculating the comparative model, data on 60 fields were used, among which AI was used at 30 selected fields for analysis of geoposition, depth of effective development, techniques and methods of oil extraction, and calculations were made using the traditional manual method at 30 remaining fields. It can be seen, that according to the average calculation factor, which included data on well productivity for the first 12 months of operation, each ruble invested in the development of the well produced a payback of 1.67 rubles, while by the traditional method only 1.44 per ruble spent. Some maximum and minimum points can also be determined, for example, the "Bazhen-South No. 16" field, produced a payback of 2.16 rubles, and the minimum value of "Bazhenov field No. 312", developed by PJSC "Gazprom Neft", is only 0.87 rubles. However, according to "Gazprom Neft" experts the overall indicator will only increase, since AI can include new data and improve methods for specific working conditions based on the information exchange and analysis, and the next time select more cost-effective decisions when developing the field in similar conditions. [6]

However, despite the success of AI experimental usage, now, there are no industrial development technologies at the fields due to significant differences in the conditions and features of production even in the same region, to say nothing of the territory of the entire Russian Federation and coastal regions. According to experts, the oil recovery factor (hereinafter referred to as "ORF") of HTR assets is less than $17 \%$, and reaching the project level of $28 \%$ even using $\mathrm{AI}$ at the current rate is unlikely. In this case, digital solutions will stimulate the process of creating development technologies. As a result, due to an increase in the project ORF and an increase in the reserve confirmation rate when using AI, the potential additional increase in recoverable oil reserves in Russia will be up to 7 billion tons, $65 \%$ of which will account for HTR. In addition, production and drilling costs will decrease by $15-25 \%$ on average in the country. The introduction of AI-based smart well technologies causes a decrease in the cost of field operating by an average of $20 \%$, which allows increasing the competitiveness of companies in terms of a "fall" in oil prices. [4]

In general, according to the Ministry of Energy, the key effect of innovative technologies will include the following: 5-10\% increase in the oil recovery factor at "digital fields", $10 \%$ decrease in operating costs at "digital fields", a decrease in capital costs at "digital fields" to $15 \%$ by 2025 , which are significant indicators within the entire oil and gas complex of Russia, allowing increasing the competitiveness of Russian oil in the world market. [4][7] 


\section{CONCLUSIONS}

The following factors affect the achievement of positive results of the introduction of artificial intelligence technologies from economic viewpoints and the development of the system to the All-Russian level with the potential to implement part of the technologies in foreign countries:

- increased government support to reduce import dependence;

- development of technological base of production of necessary elements, readiness for experiments, quick launch of pilot projects;

- consideration of significant geographical, natural and climatic differences in hydrocarbon production conditions;

- development of a methodology for assessing the effects of digital initiatives implementation;

- increase of server capacities for storing and processing information under "Big Data" systems.

One of the key tasks of smart technologies and AI introduction, in particular, in the Russian oil and gas industry in the near future, will comprise acceleration of the transition from prototypes to industrial production rates. The availability of own computer systems (software + hardware), as well as the experience of creating unique "supercomputers" by Russian scientists, will help improve technologies in the oil and gas complex and create a competitive and effective symbiosis of Russian OGC and computer construction. As a result, this will allow introducing innovative high-tech solutions to execute the main goal of the import substitution strategy - to intensify Russian oil and gas production and increase the profitability from the sale of HTR oil even at low oil prices and fluctuations in demand.

\section{ACKNOWLEDGEMENT}

This paper has been supported by the RUDN University Strategic Academic Leadership Program.

The article has been prepared within the framework of initiative research work No. 061607-0-000 entitled "A Comprehensive Solution for Improving the Economic Efficiency of the Coal Industry as a Condition for Strengthening Energy Safety of Russia", carried out on the basis of the National Economy Department, Faculty of Economics, RUDN University.

\section{REFERENCES}

[1] Kreydenko, T., Chernyaev,M., Grigorieva,E., Korenevskaya, A. (2020). Improvement of Informational and Analytical Base of Development of Russia's Fuel and Energy Companies in the Sphere of Energy Saving and Energy Efficiency International Journal of Energy Economics and Policy 2020, 10(2), pp. 504-511.

[2] Ministry of Energy of Russia. Available AT: https://minnergo.gov.ru/

[3] Russian Direct Investment Fund. Available at: https://ru.investinrussia.com/about

[4] Chernyaev, M.,V. Grigorieva, E.M. (2019). Small Energy Efficient Systems: The Key to Energy Security of the EU. «European Research Studies Journal», Volume XXII, Issue 4, pp. 558-566.

[5] Journal "Neftegaz.ru" (2018) article "Intellectual Mining ". pp.28-32

[6] Rodionova, I.A., Chernyaev M.V., Korenevskaya, A.V. (2017). Energy safety and innovative development of the BRICS States International Journal of Energy Economics and Policy 7(3). pp. 216-224

[7] Statistics on the economic return of the oil deposits. Available at: https://energybase.ru/oil-gas-field

[8] Statistics of the «Bazhenovskaya Svita» oil fields. Available AT: https://www.gazprom-neft.ru/presscenter/sibneft-online/archive/2015-may/1108060/

[9] Linnik Yu.N., Kiryukhin M.A. (2019). Digital technologies in oil and gas Complex // University Bulletin. № 7 pp. 37-40

[10] Chernyaev M.V., Rodionova I.A. (2017). Analysis of sustainable development factors in fuel and energy industry and conditions for achievement energy efficiency and energy security. International Journal of Energy Economics and Policy 7(5). pp. 16-27

\section{Article history:}

Received 30 June 2021

Accepted 8 December 2021 